\title{
De la aritmética práctica en el Perú, siglos XVI-XVII. Una aproximación
}

Recibido: 21/03/2020

Aprobado: 04/05/2020

Publicado: 25/08/2020
Juvenal Luque $L$. Universidad Nacional Mayor de San Marcos <jluquelu@gmail.com>

\begin{abstract}
RESUMEN
Esta investigación busca presentar algunos aspectos de la aritmética práctica colonial durante los siglos XVI-XVII que fue la base para entender la aritmética de las monedas coloniales, el giro del comercio, etc. En este periodo es donde diversos sectores de la economía sintieron la necesidad del auxilio de la aritmética para el giro rápido, exacto y seguro de sus negocios que descansaban en diversas monedas u otras unidades. Con este estudio se pretende no solo presentar algunos aspectos de esa aritmética y buscar vínculos existentes con la economía, adelantaremos algunas características de la práctica aritmética colonial junto a la descripción de algunas de sus reglas para ver su aplicación práctica cotidiana. Se presentará cómo la consolidación del practicismo matemático sirvió como medio de difusión de sus reglas a través de instituciones extra educativas, el ejercicio diario y la transmisión oral, ademán de los textos impresos, copias de impresos y manuscritos, en general todo debido al esfuerzo privado. Como fuentes se han usado textos impresos sobre el tema en el Perú, América o Espańa y documentos manuscritos existentes en Lima.
\end{abstract}

Palabras clave: Perú, siglos XVI-XVII, matemática

\section{Aspects of practical arithmetics in Peru, XVI-XVII centuries}

\begin{abstract}
This research seeks to present some aspects of colonial practical arithmetic during the XVI-XVII centuries that was the basis for understanding the arithmetic of colonial coins, the turn of commerce, etc. In this period is where various sectors of the economy felt the need for the help of arithmetic for the fast, accurate and safe turn of their businesses that rested in various currencies or other units. With this study is intended not only to present some aspects of that arithmetic and find existing links with the economy, we will advance some characteristics of the colonial arithmetic practice with the description of some of its rules to see its practical application everyday. It will be presented how the consolidation of mathematical practicism served as a means of disseminating its rules through extra educational institutions, daily exercise and oral transmission, as well as printed texts, copies of printed material and manuscripts, in general, all due to private effort. As sources have been used printed texts on the subject in Peru, America or Spain and existing manuscript documents in Lima
\end{abstract}

KeYwords: Peru, XVI-XVII centuries, mathematics

1 El presente trabajo en un avance de una investigación mayor en curso sobre la aritmética práctica colonial. Es el resultado del proyecto de investigación presentado por el autor al Vicerrectorado de Investigación de la UNMSM en 2017 bajo el título de "El 'babel aritmético' de las monedas fiscales. Lima, siglos XVI-XVIII” siendo miembro corresponsable Chaupis Torres José Antonio y tesista Lobo Collantes Juan Franco. 
La ciencia matemática nada nos debe: no es nuestra; no hay en ella nombre alguno que labios castellanos puedan pronunciar sin esfuerzo.

José L. Montesinos. Ciencia y teología.

\section{Introducción}

$\mathbf{L}$ a realidad económica colonial necesitó del concurso oportuno de la aritmética, que a través de promotores interesados le proporcionó los procedimientos matemáticos para solucionar sus problemas cotidianos. ${ }^{2}$ El sector del que provino este interés fue el extra académico. Las fuentes peruanas coloniales de este género (manuales prácticos de cuentas) son lo suficientemente representativas que nos permiten formarnos una idea clara de su desarrollo a lo largo del periodo colonial y dentro de ella los dos primeros siglos están representados por autores como Diez Freyle (1556), Belveder (1597), Garreguilla (1607), Saldías (1637) o Morillas (1693). ${ }^{3}$ Estas obras son fuentes básicas para presentar algunos aspectos de la aritmética práctica peruana y sus principales demandas. Estas no solo ofrecían soluciones a los comerciantes o tratantes si no a la población urbana y hasta el sector indígena que fue incorporado a la economía a través del mecanismo compulsivo del tributo. La problemática solucionada en sus páginas con procedimientos matemáticos comprendía diversos sectores económicos, claves para la economía colonial como la minería, comercio o fiscalidad. La aritmética práctica a fines del siglo XVII con Morillas se puede considerar como la más representativa de la literatura de este género, texto al que se puede llamar sin reservas manual de la aritmética práctica peruana, el summus de lo que podríamos llamar aritmética económica ${ }^{4}$ por comprender la

2 En este conjunto de textos utilitarios los descubrimientos más revolucionarios se dieron a fines del siglo XVIII donde se orientó con mayor esfuerzo hacia el sector del recaudo del quinto al décimo minero atribuible al aumento de la producción minera. Los autores de estas innovaciones fueron personajes que dieron rienda suelta a su imaginación, por la libertad que había, para ensayar nuevos métodos de cálculo, ante la inexistencia de una matemática única o estándar hasta incursionar en los tópicos de aritmética avanzada.

3 Para el siglo XVIII contamos con fuentes manuscritas custodiadas por la Biblioteca Nacional.

4 A semejanza de lo que en su momento llamó aritmética política William Petty en su Essays in Political Aritmetic (1679) refiriéndose a los actos gobierno "«el arte de razonar mediante cifras acerca de cosas referentes al gobierno"; la aritmética del que se habla sería el arte de razonar con cifras sobre hechos relativos al comercio. casi totalidad de las demandas aritméticas prácticas, acompañado de un conjunto de problemas rotulados como reglas breves o curiosas, que todo buen aritmético no podía dejar de conocer.

Para el conocimiento de este tema se escribieron un conjunto de textos que satisficieron esta necesidad. Los autores fueron un conjunto de personas que dieron a la luz pública un conjunto de tratados dirigidos a un público más relacionado con el comercio y la moneda. La necesidad de una aritmética utilitaria fue propicia para el surgimiento de las matemáticas prácticas en el Perú colonial, heredera de la metropolitana y europea. Esta tendencia hacia la matemática aplicada o práctica ha conducido a autores como Rey Pastor a pensar que en la bibliografía española de matemática hasta 1500 no hubo avances en matemática teórica y eran solo libros de cuentas y geometría de sastres (Citado por López Piñero, 1982: 6. Montesinos, 2007: 40) lo que demostraría la preeminencia de las matemáticas prácticas en el mundo colonial peruano a semejanza del español que tenía larga data.

Las reglas aritméticas o demandas que contaban con sus respectivas fórmulas, pasos o procedimientos llegaron a alcanzar a fines del siglo XVII alrededor de 30 denominaciones, algunas de ellas poco comunes como regla de anear, de reducción, de aligación, de compañía, de tres, del arrobado, de baratas, de censos, de réditos, de rédito de réditos, de falsa posición y de dos falsas posiciones, de igualación, de arqueamiento de naves, de quilatación de piedras preciosas y diamantes, etc., muchas de ellas totalmente históricas y caídas en desuso. Estas eran a su vez los diversos problemas que en la vida económica diaria debían resolverse con el auxilio de la aritmética. Cada una de estas reglas aritméticas constaba de procedimientos de cálculo bastante detallados con sus respectivos ejemplos demostrativos y pruebas reales. Por ejemplo los procedimientos de las reglas de compañía inversa no podían aplicarse a los problemas de las compañías entre oficiales y viceversa. Este uso restrictivo de la aritmética está presentado con multitud de ejemplos en la Aritmética peruana como el de Morillas. A pesar de la limitación que supuso el uso casi mecánico de las reglas, muchas veces con desconocimiento de los fundamentos que le dieron origen, los autores o 
usuarios coloniales de esta ciencia siempre encontraron un incentivo para innovar las reglas corrientes. ${ }^{5}$

La matemática se cultivó en sus dos aspectos: como disciplina teórica y como disciplina utilitaria, práctica o aplicada, esta última base de las aplicaciones prácticas en diversos campos de la actividad económica. La especulación teórica fue conocida como matemáticas puras y la segunda como matemática mixta, aplicada o práctica. La matemática pura debió ser cultivada en las universidades en sus cátedras de matemáticas. En el Perú su arraigo fue pobre y una muestra de este descuido es la fundación tardía de la cátedra de matemáticas en San Marcos (segunda mitad del siglo XVII), creada más para satisfacer necesidades prácticas de los pilotos de naves: "las matemáticas, destinada a formar expertos pilotos de mar" (Espinoza, 2012: 4, 37).

En el Perú la náutica, economía, fiscalidad o minería fueron las actividades donde se sintió una mayor necesidad de la aritmética. Ahí están como muestras representativas los manuales de aritmética escrita para satisfacer estas necesidades. Esta tendencia se apartó un poco a la condición colonial del Perú, que asumiendo su papel de consumidora y difusora de conocimiento de la cultura metropolitana o europea no creó el ambiente apropiado para el cultivo de la teoría a excepción del aspecto práctico que logró alcanzar hasta innovaciones revolucionarias. Asumir este papel pasivo en lo teórico era una consecuencia inevitable frente al papel dominante del pensamiento religioso. Aventurarse a incursionar en los terrenos de la abstracción o teoría podría suponer una ruptura previa con el orden social o cultural establecido. El cuestionamiento aunque tangencialmente formulado, era una posibilidad excluida en los marcos de una sociedad colonial (Macera, 1977: 24-26).

Este sostenido descuido de la teoría es consecuencia frente al papel dominante que jugaron la teología o la jurisprudencia por ser un mecanismo de ascenso social. En los claustros universitarios es donde debió bullir la teoría, pero en la práctica sus cátedras de Matemáticas presentaban un ambiente

Este incentivo hizo que para solucionar una determinada demanda existiera más de un procedimiento y todos ellos conducían siempre al mismo resultado. Lo mismo ocurría cuando se trataba de las operaciones aritméticas elementales como el multiplicar, campo en el que se idearon hasta unos doce métodos distintos para multiplicar para llegar siempre al mismo resultado. desolador, falto de alumnos y profesores capacitados (Villaseca Forne, 1985: 185-212). La especulación teórica en las matemáticas fue considerada como inútil y de poco provecho. En su lugar Hispanoamérica produjo textos importantes de matemáticas y tablas aritméticas prácticas donde las reducciones de monedas, barras, tejos o tráfico de pańos será la dominante al servicio del uso inmediato, luz o faro de los tratos y contratos.

\section{La aritmética práctica en el Perú}

Durante los casi tres siglos del dominio colonial el desarrollo científico se vio entorpecido por la superstición, la censura, la persecución, y en general por el predominio intelectual de la iglesia sobre la educación y el pensamiento científico en general. Parece ser que de esta censura se salvó la aritmética que sorteando la censura sin mayor problema pudo desarrollarse sin mayor limitación. En las cátedras universitarias predominaron la teología, la sagrada escritura, artes, retórica o gramática. En cambio dentro del campo del ejercicio del comercio o giro fiscal en desarrollo floreció la otra cara de la ciencia como la aritmética práctica o utilitaria.

Los diversos textos de este género publicados contenían generalmente un título largo, común en la época, fueron escritos generalmente para "facilitar las operaciones que los comerciantes en metales preciosos realizaban en el virreinato del Perú" (Moreno, 2008: 68). El método usado para explicar los cálculos era usando números enteros y quebrados dejándose de lado el complejo sistema romano o los decimales simplemente en aras de la exactitud. Este tipo de publicaciones tenía mercado porque los comerciantes, funcionarios estatales, mineros y otros gremios estaban obligados a realizar cálculos para el giro de sus negocios. Los temas predominantes en estos textos eran la numeración, adición, sustracción, multiplicación, partición, regla de tres, fracciones, progresiones, reglas para convertir o reducir monedas o determinar la liga de los metales monetarios, junto al calcular el valor de la plata u el oro según su peso y fino.

Un anónimo documento del siglo XVIII define a la aritmética de un modo silogístico como la ciencia de los números, a estos como un conjunto de unidades, y a la unidad como la cantidad que se toma "las más veces a ar- 
bitrio por término de comparación" (ejemplo 20 libras donde la libra es la unidad). ${ }^{6}$

Finalmente la cantidad era todo lo que se concebía compuesto de partes que se miden o se numeran. Para el siglo anterior en México el concepto de aritmética era similar según definición del mercedario fray Diego Rodríguez: "ciencia de los números y de sus propiedades en abstracto" (Trabulse, 1984: 70 y ss.). Un tercer autor define la aritmética como una ciencia que trata de los números. "Divídese en Theorica, y Práctica. La Theorica trata de la naturaleza del número, y de su difinicion, división, y comparación. La Práctica trata el orden de investigar, y hallar los números dudosos demandados, con cuyo auxilio venimos en conocimiento de lo que se ha de usar á cerca de los tratos de la vida humana, para no defraudar, ni ser defraudados" (Atienza, 1776: 1). Este último era fin y suprema utilidad de estos tratados, no defraudar o no ser defraudados, no engañar o no ser engañados, no errar o que otros no yerren.

Definida la aritmética como la ciencia de los números, esta aritmética está representada en la Arismética Peruana del hermano Diego de Morillas, su obra nos puede dar una idea de lo que en el siglo XVII era el objeto de la aritmética práctica. El texto muestra que aún los problemas aritméticos no se resolvían por procedimientos algebraicos ni se intentó generalizar las reglas matemáticas a una fórmula general con el concurso de variables simbólicas ni invocar el uso de los decimales que hubiese simplificado los cálculos. ${ }^{7}$ Esta limitación les impidió valerse de este auxiliar junto a la desventaja que supuso la no generalización del uso de los números decimales en las operaciones aritméticas. Esto no nos impide negar que en sus procedimientos de cálculo ideados

6 Biblioteca Nacional de Lima, Sala de Investigaciones Bibliográficas (BNSIB). Tratado de aritmética. Mss. s/f. El contexto de la redacción parece indicar como correspondiente al siglo XVIII.

7 Los números decimales eran conocidos ya a la llegada de los españoles pero se sacrificó su uso en el periodo colonial en aras de la exactitud. estuviera implícita una fórmula. Solo faltó pasar de la etapa descriptiva del procedimiento a su formulación algebraica simbólica. ${ }^{8}$

El ejercicio de la aritmética respondió a los siguientes principios resumidos en las siguientes frases ilustrativas: mayor galantería es ahorrar números, resolver un problema en un instante, buscar un atajo admirable para sacar de una vez, buscar ahorro de muchos números y papel especialmente, será mejor contador quien con menos número sacare una cuenta, simplificar lo anteriormente simplificado era hallar un atajo de atajos, siempre era mejor buscar el número menor para que la operación fuera con menos

TABLA 1

Tabla para convertir pesos corrientes de 9 reales a pesos ensayados ${ }^{*}$

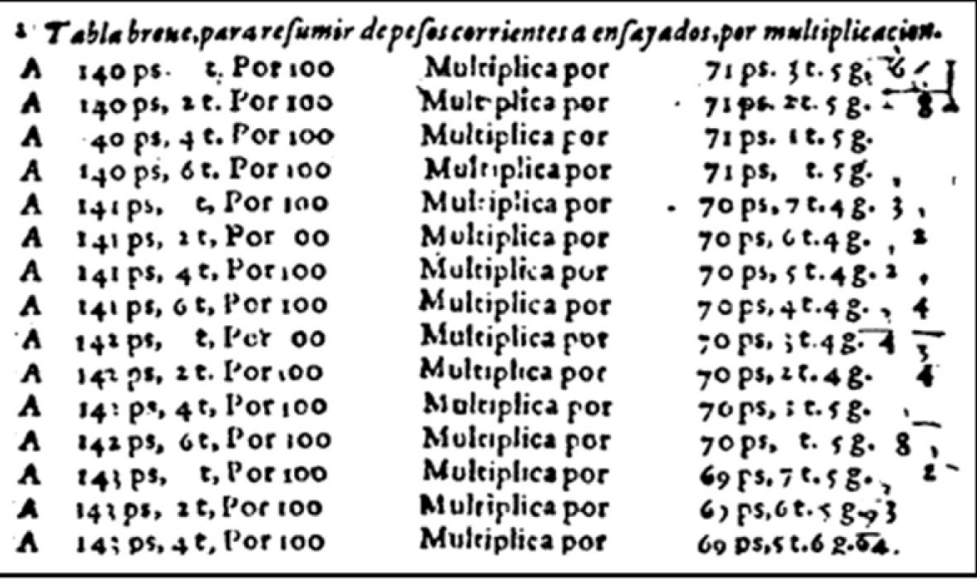

Fuente: Belveder, 1597, fol. 72.

* Esta tabla era útil para situaciones como la siguiente: quiero convertir 15.800 pesos de 8 reales a pesos ensayados sabiendo que el precio era de 143 pesos 4 reales (pesos de 9 reales) por cada 100 pesos ensayados, bastaba multiplicar, usando esta tabla, los 15800 por 69 pesos 5 tomines 6 granos $3 / 4$ de maravedí para obtener los 15800 pesos como comprobación.

números (Morillas, 1984) que a su vez están representadas en las cuentas breves o abreviadas. Además la confección de tablas fue una puesta en práctica de los principios anteriores. ${ }^{9}$ Su observación hizo que la práctica aritmética fuese de corte personal, inventiva (búsqueda de nuevos métodos, nuevas reglas breves

8 Las reglas matemáticas de la reducción de barras, aunque descrito por Morillas literalmente, es perfectamente posible expresarlo mediante una fórmula algebraica: $\mathrm{BR}=(\mathrm{BO} * \mathrm{~L}) / \mathrm{LB}$ donde $\mathrm{BR}$ es el peso de la barra reducida, BO peso de la barra objeto de la reducción, L ley o fineza de la barra anterior y LB fino de la barra reducida. Con la fórmula anterior se puede calcular cualquiera de las variables conociendo las tres restantes. La llamada regla de la falsa posición se aproxima más a los modernos problemas algebraicos para resolver los problemas.

9 Prácticamente todos los autores se han validos de las tablas para representar sus aportaciones. 
o curiosas), muchas veces redundante, plasmada en un conjunto de reglas aritméticas, de las que el uso práctico hizo olvidar, muchas veces, los fundamentos de su creación.

La aritmética peruana está representada en su lado práctico para los siglos XVI y XVII por los textos de Diez Freyle (1556), Belveder (1597), Garreguilla (1607), Saldías (1637) y Morillas (1693), quienes desde su punto de vista y respondiendo a las necesidades de su época presentan temas o problemas en sendas tablas prácticas. Una breve referencia a sus obras nos indicará los temas aritméticos al que dieron preferencia los autores en su momento y en conjunto muestran el panorama de la práctica aritmética peruana, presentada a veces con textos explicativos o de divulgación (Morillas) o exclusivamente como tablas aritméticas (Garreguilla) donde es posible reconstruir las técnicas aritméticas usadas para la confección de las mismas. Esta sola posibilidad convierte a estas tablas en fuentes para el estudio de la aritmética colonial aunque en sentido estricto no son manuales de aritmética pura.

La Arismética peruana de Diego de Morillas $^{10}$ (1693) tiene el merito singular de consignar en un solo texto más de 30 reglas aritméticas prácticas con sus respectivas explicaciones, no comunes en textos anteriores. Su preocupación principal es ocuparse exclusivamente de la aritmética peruana y sus problemas. Esta amplitud de temas incluidos por él hacen que su obra sea tomado como un manual de aritmética práctica y su contenido como los temas del que ella se ocupaba a fines del siglo XVII. En esta calidad las características de la práctica aritmética que en su texto menciona pueden atribuirse a la que un buen aritmético debía conocer para no cometer errores en los cálculos. El contenido de su obra no tiene parangón con sus antecesores, simples tablas de reducciones, al incursionar en una aritmética de corte pedagógico, exponiendo los fundamentos de cada uno de las reglas del que se ocupa. En las tablas aritméticas anteriores estos fundamentos se suponían conocidos o sobreentendidos.

10 Las referencias biográficas reunidas por Anne Marie Davée sobre Morillas son escasas. Aparte de su condición de religioso y desempeñar muchos oficios modestos tenía experiencia en la administración de haciendas donde pudo adquirir habilidad en cuentas, además de la docencia. Nació Morillas en el Cusco en 1638, desconociéndose los datos relativos a su infancia y adolescencia. En 1661 ingresa al seminario jesuita a los 23 ańos.
Morillas ${ }^{11}$ se propuso no ocuparse expresamente de cuestiones tocantes a la teoría aritmética aunque muchas veces roza este aspecto en varias partes de su obra (aritmética de los quebrados), por juzgarlo de innecesario remitiendo a otros autores sobre estos tópicos. El objeto de la aritmética en Morillas es muy amplio al incluir diferentes tópicos que iban de las elementales 4 reglas, pasando por las reglas de las compañías, testamentos, aneages, reducciones, etc. $\mathrm{Al}$ estar dedicado su obra a los comerciantes volcó en su páginas todo el rompecabezas que era pensamiento práctico del comercio colonial que, a su vez, estaba ligado íntimamente a las monedas. En la mayoría de sus reglas o demandas estaba presente siempre algún tema relacionado con el comercio. Los que aparentemente escapaban de este norte no figuran en Morillas. Tal es el caso de la aritmética del quinto de barras de plata y tejos de oro. La única explicación de su exclusión por Morillas es suponer que estos tópicos no eran de interés del comerciante común o que hubo comerciantes especializados dedicados exclusivamente a este giro. El comercio era solo uno de los usuarios del metal oro o plata previamente quintado con certificación expresa de su ley y peso para evitar fraudes, recurriendo a la técnica de la moneda imaginaria o de cuenta para habilitarlos como moneda mayor.

Sus labores de maestro en el Colegio Seminario de los Caciques de Lima (1681) o administrador de la hacienda Cacamarca o Cacamalca (1685) debieron impulsarlo a emprender a redactar un manual donde volcara su experiencia y suplir las faltas advertidas en el mundo de las cuentas y relativas al Perú. Se consolida su convicción después de una estadía en Potosí, empezando la redacción de su aritmética hacia $1691,{ }^{12}$ una vez constatado en el campo la necesidad de un manual de este tipo. El resultado fue su Aritmética peruana (1693).

11 El descubrimiento del trabajo de Morillas es una muestra completa del universo temático de la aritmética práctica. Para su redacción Morillas volcó parte de su experiencia personal además de usar obras similares donde los temas peruanos de los negocios solían estar ausentes. Una lista de los autores que cita y usa da testimonio para considerar a su obra como la suma de la aritmética práctica colonial. Su experiencia personal en el tema puede inferirse por su procedencia jesuita, instituto religioso y a la vez una poderosa y bien organizada empresa económica, junto al de administrador de una hacienda. Esta doble procedencia se refleja en la dedicatoria de su obra: a la Virgen María y al prior del Consulado limeńo.

12 Morillas 1984, al lector. 
Una gran interrogante que resulta inquietante es la razón de intitular Arismética peruana a su manual de aritmética aplicada. La respuesta en gran medida está en las páginas iniciales de su texto. Su objeto al emprender la obra no fue ocuparse de la definición del número si no de todas las cuentas husuales y necesarias en este Reyno del Peru, con los pesos, medidas y monedas que en el corren, ausentes en tratados similares. El subtítulo de la obra aclara el objetivo que persiguió: cuentas y reglas de ellas (Perú) mui usuales y necesarias [...] para todo género de comerciantes, en que hay reducciones de oro y plata y reglas mui curiosas. Al ser los patrones de pesos, medidas y valores propios del Perú, diferentes de los países europeos e incluso de Espańa con denominaciones propias y patrones de equivalencia distintos, exigía un trato especial. La particularidad del sistema metrológico fue en última instancia la razón que animó para denominar a su aritmética como peruana. Una muestra de este particularismo es la profusión de cuentas, problemas o demandas siempre relacionados de alguna manera con los tratos y contratos que ocurrían en el Perú. En tanto manual educativo su obra estuvo dedicada tanto al principiante (reglas de las 5 operaciones elementales) de los que se habla en los conciertos citados por Valcárcel (1968: 30-31) como a los avanzados en cuentas que podían usar las refinadas técnicas de los apartados signados como de cuentas curiosas y breves. Su objetivo final no fue más que dedicarlo al usuario peruano para "dar luz en tus tratos o ocupaciones para que sepas hacer una cuenta sin que te cueste el empacho de que otro de la aga" (Morillas 1984: 639).

Lo extenso de su trabajo tiene el mérito adicional de redescubrir los fundamentos de algunas cuentas que quedaron en el olvido con el correr de los años. Tal es el caso del ensayado en la barra donde las reducciones se habían convertido en la práctica mecánica de sacar "la cuarta parte, cortar 4 números [...]" sin saberse la razón o el por qué operar de esta manera. Este olvido hacia de las operaciones de reducción se parecía en algo similar a la de los médicos que simplemente hacían: recetar purgas por doquier sin saber las cualidades de sus ingredientes, y solo ante el convencimiento de su bondad.

En varias secciones de su Aritmética Morillas incursiona en tópicos reservados al álgebra y los problemas de este tipo los trató a pesar de expresar expresamente que no lo tocaría porque su objetivo era otro:
"[...] sin adelantarme a cossas mayores que mi rudeza no alcansa, como son las intrincadas del arte mayor, extracción de raices, vinomios, reciduos y progresiones para lo qual hallaras famosos autores que te lo enseñen" (1984: 639). Al ignorar Morillas el uso de variables algebraicas los problemas de este género los resolvió basándose en métodos estrictamente aritméticos, recurriendo a técnicas como la del número fingido, número buscado, la cosa, el número falso o la falsa posición. Los problemas propios para soluciones algebraicas fueron agrupados en la sección reglas de dos falsas posiciones y de la primera igualación o "de la cosa". La relación con el álgebra puede apreciarse en los siguientes problemas: "dame tres números, que el segundo sea duplicado del primero menos 12 y el tercero sea triplicado del segundo más 10, y todos tres sumen 820"; o ¿yo tuve en un talego cierta cantidad de dinero, no me acuerdo cuánto. Solo me acuerdo que en alguna ocasión saqué la mitad y en otra el tercio y por último 379 pesos. Cuántos pesos serian todos? o uno tenía en Lima cierta cantidad de dinero en poder de tres comerciantes. No se acuerda cuánto era el todo, solo se acuerda que en poder de uno tuvo la tercia parte menos 130 pesos, el poder del segundo la cuarta parte más 85 pesos y en poder del tercero 720 pesos; etc. (Morillas, 1984: 499 y ss.) La solución de estos problemas en Morillas se hizo sin el concurso de símbolos, variables ni fórmulas, correspondiendo su método a la fase primitiva del desarrollo del álgebra llamada retórica, donde las operaciones se describían textualmente, usado en Europa hasta el siglo XV (Sedgwick y Tyler, 1950: 155).

En sus páginas dedicadas a temas algebraicos los problemas comerciales no faltan y el método usado por él para solucionarlos no discrepa en nada a la de Luca Pacioli: uso de procedimientos árabes como el de las hipótesis arbitrarias que en Morillas esta cambiado como número fingido. Un ejemplo de este método introducido en Europa por Pacioli aproximará Morillas a la realidad peruana: "encontrar el capital inicial de un mercader que gastó la cuarta parte del mismo en Pisa y la quinta parte en Venecia, que en esas ciudades recibió 180 ducados y que tiene actualmente 224 ducados" (Sedgwick y Tyler, 1950: 267). El cálculo del capital inicial se podía hallar por suposición.

Cronológicamente el texto del valenciano Francisco Juan de Garreguilla (1607), inmediata- 
mente anterior a Morillas, fue impreso en Lima por Francisco del Canto. Sigue la misma política de dirigir su obra a los "mercaderes y personas que tratan con la plata". Este norte utilitario de su texto fue confirmado por los pareceres que preceden al texto como el del contador Lorenzo López de Gamiz: obra "util y necesaria para la contratación de estos reynos", con la ventaja adicional de ser más clara y de fácil manejo de lo hasta esa época publicado, subsanando las deficiencias de Belveder. Las soluciones estaban en "una linea o renglón" cuando en Belveder aparecía separado. Aunque los temas no son totalmente distintos al del dominico Diez Freyle, el de Garreguilla fue juzgado en su época como "más util y necesario para el trato y comercio del reyno del Perú", ${ }^{13} 14$ sobre todo para el despacho breve de las armadas rumbo a Tierra Firme y saber con facilidad el valor de cualquier barra de plata en pesos corrientes, pesos de 8 reales con sus intereses.

Los textos aprobatorios preliminares confirman que las tablas prácticas de Belveder habían cumplido su ciclo y la de Garreguilla venía a responder a las nuevas necesidades, subsanando las dificultades del texto anterior. Su mérito fue el de ser recibido con singular aprecio porque en él se podía hallar con facilidad el valor de cualquier barra de plata expresada en diversas monedas (peso ensayado, pesos corrientes y pesos de a 8 reales) con los intereses del caso. Una prueba que satisfizo su utilidad práctica fue el siguiente: con el tiempo que se invertía en reducir una barra de plata con el texto de Belveder a la vista, en el mismo término siguiendo a Garreguilla se podían reducir 10 barras de plata "con sobra de tiempo", factor muy tomado en cuenta para el breve despacho de los armadas, negocios y cuentas en el Perú.

Como sucedía con textos mercantiles prácticos de su época el sector al que estuvo dirigido el libro de Garreguilla fue el giro de los mercaderes, y el tema que ocupa gran parte de su obra es el cálculo del valor de las barras de plata expresadas en las monedas corrientes de la época, tomando en cuenta los precios comerciales: desde 30 hasta 129 marcos de fino total (2.380 maravedís). ${ }^{14}$ Añadió algunas tablas complementarias y sobre todo el valor de las barras de plata (de 30 hasta 125 marcos de 2.380 maravedís) pero

13 Aprobación del contador Luis de Morales y Figueroa.

14 Este valor es un redondeo del valor original de 2.376 que es el fino total de la plata. Se redondeó para facilitar los cálculos de conversión. expresados en patacones valorando los pesos ensayados a 12 reales y medio $(12,5)$.

Garreguilla presenta en sus tablas lo relativo a la "plata reducida" como lo insinúa el titulo, calculando sus valores a partir de los 30 marcos. Estas barras en la práctica eran fundidas en las callanas reales con un peso promedio de 100 marcos. Su preocupación no excluía la posibilidad de escribir un libro donde trataría exclusivamente de los barretones ${ }^{15}$ de peso y leyes bajas (por debajo de los 30 marcos y 2.380 maravedís de fino). Sus tablas de plata reducida estuvieron íntegramente dedicadas al valor de las "barras de buen peso y de (buena) ley". No tenemos noticias sobre la publicación prometida acerca de los barretones de plata que debió tener la misma estructura del que aquí se menciona. Entretanto sus extensas tablas podían ofrecer soluciones como a la siguiente pregunta: Pedro debe por escritura pública a Juan 764 pesos corrientes y 7 reales, ¿`cuánto equivalen en pesos ensayados o en marcos de toda ley?

Un tercer texto ofreció Garreguilla dar a publicidad en el que prometió completar sus reducciones incorporando el tema del oro reducido, que requería un trato diferente por la naturaleza de requerir tan prolija cuenta. Este texto fue redactado paralelamente al de la plata reducida en el que pensó incluir las reducciones del oro de todas las leyes, y reducido a la precisa de 22,5 quilates. La necesidad de libros de oro reducido era evidente porque en sus tratos se requería hacer tantas cuentas "que provoca mareos a un entendido", pudiéndose imaginar lo que le causaría a un principiante o neófito. Sus palabras acerca del nuevo libro que iba redactando confirman sus propias palabras: "déjolo para el libro de las reducciones del oro que voy acabando y en el trataré de algunas reglas curiosas y fáciles". Sobre la impresión de este tercer texto no tenemos conocimiento.

Cronológicamente el libro inmediatamente anterior a Garreguilla fue el de Juan de Belveder (1597), natural de la villa de Tauste, publicado por el introductor de la imprenta en el Perú Antonio Ricardo. $\mathrm{Al}$ igual que sus similares posteriores su texto fue elaborado para uso en las contrataciones del Perú: "de mucha utilidad para los mercaderes y personas que trataban", evitando fraudes y engaños en las cuentas.

15 Los barretones eran barras de plata de peso inferior a los 100 marcos (1 marco equivalía a 230,045 gramos modernos). Este probable libro pudo titularse Libro de barretones reducidos. 
La temática de sus tablas es similar a los textos de su género: reducciones e intereses expresados en diversas monedas, con algunas reglas y avisos curiosos necesarios en el Perú.

En las palabras al lector reitera Belverder ser su texto de aplicación en el Perú donde corria la "mayor grossedad de riquezas, siendo las dos principales riquezas el oro y la plata, además de las perlas y piedras preciosas”. Los textos de aritmética práctica, aún bajo la forma de tablas extensas en Belveder, eran necesarios porque no todos los usuarios o personas tratantes eran expertas en cuentas, pudiendo fácilmente incurrir en yerros. Este argumento de la falibilidad en las cuentas era una razón poderosa para incluir en estos textos las tablas de los temas relativos a reducciones de barras. En Belveder las reducciones de barras parten de 1.000 maravedís de valor hasta 2.400 reducidas a pesos ensayados, tomines, granos, maravedís y cuartos de maravedí; además de la del oro y junto a las de monedas: de "unas a otras y de otra a otras", siempre acompañado de las habituales reglas abreviadas necesarias.

El Sumario compendioso de las cuentas de Juan Diez Freyle ${ }^{16}$ fue el primer libro de matemáticas publicado en América (1556) por el introductor de la imprenta en México Juan Pablos. Estuvo dedicado también a las cuentas de plata y oro que eran necesarias a los mercaderes y cualquier género de tratantes en el Perú como lo indicaba el título. Su preocupación principal, indicada por la cantidad de páginas, fue la reducción de barras de plata y tejos de oro. Los primeros reducidos desde 1.500 a 2.400 maravedís de ley y los segundos desde 1 hasta 24 quilates. Los resultados de estas reducciones fueron presentadas en forma de tablas y no tenía otra finalidad práctica que el de ayudar a calcular sin mucho esfuerzo el valor de cualquier barra de plata o tejo de oro, de peso y ley diferentes. Un segundo grupo de tablas está dedicado el cálculo de los intereses (hasta 30\%) que se acostumbraba dar por la plata y oro. Como información complementaria se incluyen tablas sobre el valor de

16 Existen tres ediciones muy conocidas de esta publicación: Edic. facsimilar por Cultura Hispánica del Instituto de Cooperación Iberoamericano, 1985. Edición en inglés: Smith, David Eugene. The Summario Compendioso of Brother Juan Diez. The Earliest Mathematical Work of the New World. Boston y Londres, 1921, con nota introductoria de más de 80 páginas. Reedición mejicana con estudios preliminares de 2008. El original se halla en la Biblioteca de la Universidad de Salamanca. la plata corriente, de la plata quintada, del diezmo y las reducciones de monedas. Las reducciones monetarias eran necesarias ante la concurrencia de diversas unidades monetarias extranjeras, españolas y americanas: peso de oro de Tepuzque, peso ensayado, coronas, ducados, pesos de buen oro, etc.

\section{TABLA 2}

Reducción de la plata de 1.500 maravedís de fino a marcos, onzas y cuartas

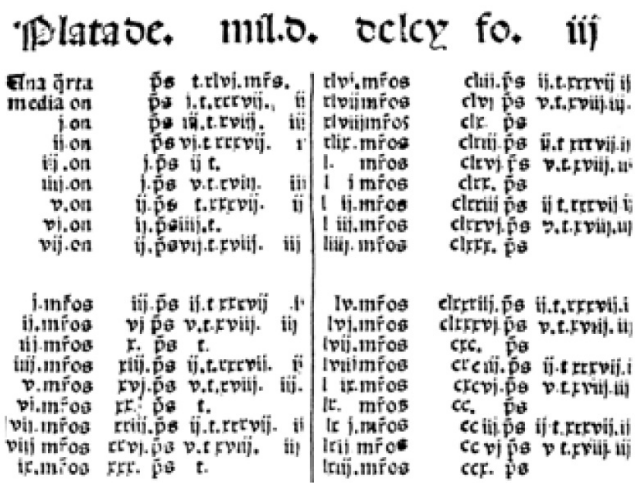

Fuente: Diez Freyle, 1556, folio iii.

El texto de Diez Freyle puede considerarse como un texto de matemáticas por sus aportes teóricos consignados en la sección de notables cuestiones del arte mayor reservadas al álgebra, incluida como información para curiosos. En otra sección rotulada como de reglas ordinarias hay un grupo selecto de problemas sobre tópicos relacionados con el arte de la aritmética (reglas breves y curiosas, números cuadrados y cubos), con detalles importantes para reconstruir la confección de sus tablas.

Los problemas y soluciones incluidas en la sección de notables cuestiones del arte mayor, Diez Freyle usó procedimientos de solución matemáticos considerados como muy novedosos para su época. $\mathrm{Al}$ abordar los novedosos temas de las ecuaciones cuadráticas sus soluciones fueron juzgadas de aporte original (Hernández Ch. y Niño G. (coordinadores), 1991, vol. 2). Estos problemas relacionados con las ecuaciones tienen el texto siguiente: "dame un numero cuadrado que restando de el 15 y $1 / 4$ quede su propia raíz", o "uno tiene yeguas y vacas en quintupla proporcion de tal suerte que si multiplicas las yeguas en si y al producto sumas seran 1694, demando cuantas son las yeguas y cuantas las vacas" (Diez Freyle, 1556, fs. 101 y ss). En la solución de problemas simi- 
lares recurrió Diez Freyle a una serie de tecnicismos y métodos como el de la cosa (similar al número fingido en Morillas). Un mérito adicional del texto de Diez Freyle es la de usar los números arábigos en un texto matemático, a pesar que los números que usa con profusión a lo largo del texto es la romana, sobre todo en la presentación de las tablas.

\section{Principales demandas}

La temática, que es común en los autores de aritmética práctica colonial, no es original "sino que siguió el esquema de las aritméticas italianas de su siglo (XVI), que con frecuencia contenían tablas que buscaban reducir al mínimo los complicados procedimientos numéricos necesarios para establecer las equivalencias entre pesas, medidas, determinación de porcentajes y cambio de moneda" (Moreno 2008: 71).

Muchas de estos autores fueron comerciantes y escribieron su tratados con conocimiento de causa como es el caso del aragonés Juan de Belveder que quedó registrado en los protocolos notariales del siglo XVI y por lo tanto estaba habituado al manejo de las diversas monedas vigentes en la época

(Suárez 2014: 30). Entonces no era hábil solo en los entresijos del comercio sino también en la aritmética monetaria que habría sido los conocimientos que lo animaron a escribir su libro. Sabedor de que podía sacar provecho de sus habilidades contables quedó constancia documental porque ofrecía sus servicios como contador a principios del siglo XVII (Suárez 2014: 32). La dificultad de las cuentas con monedas procedía básicamente de que no se recurría al uso de decimales en las cuentas usándose en su lugar los quebrados lo que dificultaba la aritmética de las conversiones monetarias, y se complicaba más con el cambio frecuente de los intereses. Lo común para reducir las barras de plata era recurrir al concurso de los pesos de 9 reales que facilitaba su reducción a su equivalente en pesos de 8 reales, porque sabiendo que su valor podía ser $143 \%{ }^{17}$ se podía reducir a los patacones sin mayor problema.

Los diversos autores argumentaban también que la utilidad de sus textos radicaba en que iban dirigidos a personas que no eran expertas en el tema.

17143 pesos de 9 reales por cada 100 pesos ensayados.
Autores como Belveder en la "Epístola al lector" argumentaba que los comerciantes y personas que tratan eran "poco praticos y aspertos en la cuenta que les es necesario saber de las reduciones de unas monedas a otras, y del valor de cada una dellas, porque suben y baxan sus intereses a más y a menos precio en muchos tiempos del año". El desconocimiento de estas cuentas de las reducciones con sus intereses podía conducir a errores, fraudes o engaños que podían deberse a tres causas: el descuido, no ser hábiles en las cuentas y el ser confiadas en sí mismos cuando ensayaban las cuentas como "papagayos"; junto al reiterado argumento de ahorrar el trabajo y tiempo al momento de hacer las cuentas. Este autor y otros también alegan en su favor el ahorrar el trabajo de hacer las conversiones a los usuarios evitando el consumo de tiempo, papel y tinta. Belveder en su libro ofrecía las siguientes ayudas utilitarias:

1. Valor de barras y tejos de oro según su peso desde 1.000 hasta 2.400 maravedís el marco

2. Tablas de conversiones de pesos ensayados a corrientes (y viceversa) con intereses desde el 8 hasta el 50\%

3. Tablas de conversión de pesos ensayados a buen oro yviceversa

4. Idem de pesos ensayados a ducados

5. Idem de ducados a pesos ensayados

6. Idem «de muchas monedas y reduciones de unas a otras, y de otra a otras, desde menor a mayor cantidad, en qualquier especie dellas».

Por último, igual que muchos autores de este género de literatura, estos autores remiten a otros autores como soporte de la validez de sus textos y que no lo consideren ignorante de las matemáticas académicas, y sugerían a los clásicos en estos temas como Juan Pérez de Moya, Tartalla, Euclides, Oroncio, Luca de Burgo o Juan de Ortega.

\subsection{Las cinco reglas $^{18}$}

Prácticamente todos los autores que han escrito sobre aritmética se han esforzado en explicar las 4 operaciones fundamentales y servían a la vez como manual de instrucción para todo aquel que quisiera conocer la

18 Estas cinco operaciones o reglas elementales eran sumar, restar, multiplicar, medio partir y partir entero. 
aritmética de manera autodidacta. Se escribían para que "[...] qualquiera podra, sin maestro, aprender a contar [...]" (Atienza, 1776). Las reglas elementales de la aritmética debían ser proporcionadas por la educación elemental e intermedia colonial. No siempre a ellas concurría el grueso de la población quedando un sector considerable de la población colonial sin recibir aún la educación elemental. El sector privado concurrió a la difusión de las reglas aritméticas elementales a través de mecanismo creados por él. El concurso de maestros privados fue un mecanismo complementario para la utilidad social de la práctica aritmética. Los autores que han escrito sobre este tema a su vez podían ofrecer sus servicios como instructor o perito en cuentas como es el caso de Joan de Belveder (Suárez, 2016: 32). El mecanismo de aprendizaje no fue otro que los conciertos privados celebrados entre maestros y alumnos (a través de sus padres o apoderados) que aproximaba a los segundos a una educación especializada. A fines del siglo XVI los mercaderes o sus hijos fueron los grandes consumidores de este servicio calificado. En 1564 el mercader Pedro de Herrera contrató a un maestro para educar a su hijo en temas como aprender a "leer e escrivir y contar". Un segundo maestro fue contratado para el mismo propósito además de la precisa de "hacer una barra y tejuelo de oro y pagar dézimos y quintos". Uno tercero en 1585 debía adiestrar a su alumno para "hacer un tejo y una barra" y uno cuarto se comprometió a enseñar con internado las "cinco reglas de la cuenta" (Valcárcel, 1968: 30-31). Estos casos no debieron ser aislados y su difusión debió continuar durante el siglo XVII. Era un mecanismo ideal para acceder a una educación especializada constituyéndose en alternativa frente a oferta que provenía de la lectura de manuales prácticos. ${ }^{19}$

Estas cinco reglas elementales eran la base de toda práctica aritmética y el conocimiento de sus reglas habilitaba para comprender la estructura de operaciones más complejas. Las soluciones de todas estas operaciones no escaparon a la característica de de la aritmética colonial que toleraba más de un procedimiento para resolver cualquier problema, por más simple que fuera. Habilitado el camino para la existencia de muchos procedimientos para resolver un problema el usuario podía acudir a cualquiera de

19 Otro sector económico donde eran común estos conciertos era el gremial de artesanos ligados más a los metales preciosos con los que trataban. ellos para solucionar sus problemas prácticos o inventar ellos un nuevo método. Esta norma explica el que se hayan ideado varios métodos para realizar una suma, resta, multiplicación o división y en todos los casos ellos ofrecían siempre el mismo resultado pero por caminos distintos.

La operación aritmética del sumar fue definido como el juntar varias cantidades de una especie en una, ${ }^{20}$ y que en la práctica al ser aplicado a diversos productos y problemas complejos las reglas aritméticas del sumar recibieron diversas denominaciones: llanas, de quebrados, compuestas, etc. La primera de ellas era la más elemental consistente en reunir varias cifras de una especie en una sola cifra de la misma especie, previa ordenación de las cifras parciales según sus valores posicionales: unidades, decenas, etc. El segundo modo de realizar una suma se presentaba cuando se intentaba sumar especies en que intervenían unidades de peso con sus submúltiplos, común en las pulperías urbanas, sector comercial, minero o hacendario. Una regla aritmética prescribía por ejemplo no hacer caso de las menudencias, centavos ni de quebrado de quebrados, situaciones que se presentaban necesariamente al operar con monedas, pesas y medidas. Este apartamiento de la rigurosidad matemática fue una tolerancia aprobada implícitamente por los usuarios al no reclamar que la cuenta se hiciese hasta calcular los centavos de maravedís, tolerado ante la falta de moneda de baja denominación, aligerar las cuentas y ser práctica común. En las reglas de sumas de compuestos se buscaba juntar varias cifras de especies distintas en una sola de sus respectivos géneros: sumar quintales, arrobas y libras y las sumas totales parciales reducir a unidades menores a mayores según las necesidades.

Las reglas del restar se ocupaban de rebajar una cantidad menor de una mayor. Al igual que su antecedente en ella se presentaron modalidades del restar llamadas restar llano, de quebrados y compuestos. En la resta llana bastaba con colocar la cifra mayor primero y la menor debajo alineado por el margen derecho. Sus reglas eran similares a la moderna práctica del restar. Las restas de compuestos se hacían de la misma forma con la advertencia de si el minuendo

20 La definición moderna de la suma no ha variado en nada: “[...] es una operación directa o de composición que tiene por objeto reunir en uno solo los valores de varios números" (Postigo, 1977: 15). 
era menor que el sustraendo se "prestaba" 1 equivalencia del múltiplo, ejemplo:

\begin{tabular}{lllll} 
Deuda & 83 quintales & 1 arrobas & 1 libras & 6 onzas \\
Pago & 18 & 3 & 15 & 11 \\
\hline Resta & 64 & 1 & 21 & 11
\end{tabular}

Como en el ejemplo anterior era imposible restar 11 onzas de 6 onzas, las reglas del restar compuestos prescribían "sacar una libra de su clase anterior". Como 1 libra contenía 16 onzas, éstas sumadas a las 6 preexistentes hacían 22, y hecha esta operación recién se podía proseguir con la resta: $22-11=11$ onzas.

La multiplicación fue considerada como una de las reglas aritméticas más importantes en todo género de tratos y contratos. Su propiedad de ser una suma abreviada no era desconocida y fue la base para el desarrollo de métodos abreviados de multiplicación. El aprendizaje elemental de esta regla de la aritmética implicó el conocimiento de las tablas de multiplicación "salteada, al revés y al derecho" (Morillas 1984: $33)^{21}$ como un mecanismo para salvar el embarazo de su posible yerro al operar con multiplicaciones.

Como no podía suceder lo contrario la operación aritmética del multiplicar no se apartó de las características de la aritmética práctica colonial. Se idearon muchos procedimientos, recopilados algunos por Diego de Morillas, y todos ellos siempre conducían al mismo resultado. De esta norma no escaparon las pruebas de la multiplicación (prueba del 9 y del 7). Tampoco esta regla aritmética fue ajena a métodos curiosos o abreviados hoy caídos en desuso u olvido.

En las aplicaciones prácticas de la multiplicación, más en la partición o división, era inevitable la aparición de quebrados, exigiendo dos formas de tratamiento: uno riguroso y otro no riguroso (el primero más usado en teoría con operaciones de quebrados, como mecanismo de adiestramiento). La multiplicación de quebrados no rigurosa o aproximativa fue adoptada como un mecanismo de escape a las complicaciones en el proceso del cálculo aritmético. Esto suponía en la práctica no involucrar a fracciones diferentes de los cuartos en las cuentas al redondear cualquier fracción a uno de los cuartos $(1 / 4,2 / 4,3 / 4)$, redondeos a los que se le dieron la denominación de redondeos largos

21 La publicación de este año consta de cuatro tomos con paginación correlativa. o escasos, y cortos. Esta situación se podía presentar al operar con quebrados en la que intervenían unidades de peso, valor (monedas) y medidas.

La parte más dificultosa de las operaciones de multiplicar quebrados ocurrían con el concurso de quebrados en el multiplicador y multiplicando. Tal era el caso de la siguiente reducción al querer calcular el valor de las varas en pesos de a 8 reales:

\subsection{8 varas $3 / 4^{*}$ \\ 384 pesos 3 reales $1 / 4$}

Las reglas aritméticas para resolver la cuenta antecedente, recurriendo a las técnicas de multiplicar quebrados, constaban de rigurosos pasos que debían seguirse al pie de la letra. El resultado era una operación extensa y engorrosa (Morillas 1984: 40 y ss).

Además de la multiplicación de quebrados mencionada, existieron procedimientos de multiplicar como el común o corriente que fue conocido como de estilo ordinario, el multiplicar por número refriego (formado a partir del producto de dos números o por los elementos de este producto: 48 de 6 y 8), "multiplicar sumando", y "multiplicar restando". Cada uno de estos procedimientos de multiplicación tenían sus propias reglas de operación y hasta estaban dirigidos a determinados usuarios (los quebrados a los comerciantes o el multiplicar sumando apto para los rudos o torpes en realizar multiplicaciones complejas).

En las multiplicaciones con presencia de números refriegos el producto final se calculaba multiplicando el número por cada uno de los componentes de aquel número sucesivamente:

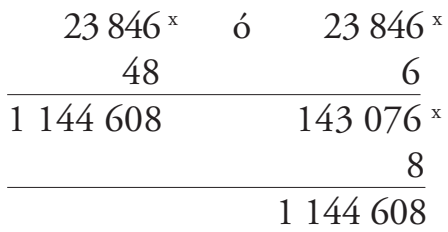

Como las reglas de multiplicar del "estilo ordinario" no siempre fueron de la comprensión o entendimiento de todos el "multiplicar sumando" era apto para quienes no estaban habituados a las multiplicaciones. Aprovechando una de sus propiedades de la multiplicación, bastaba para usar este procedimiento con construir una tabla de dobles, triples, etc. del multiplicador y utilizar estos valores por cada digito del multiplicador 
correspondiente, corriendo siempre después de cada multiplicación un espacio hacia la izquierda:
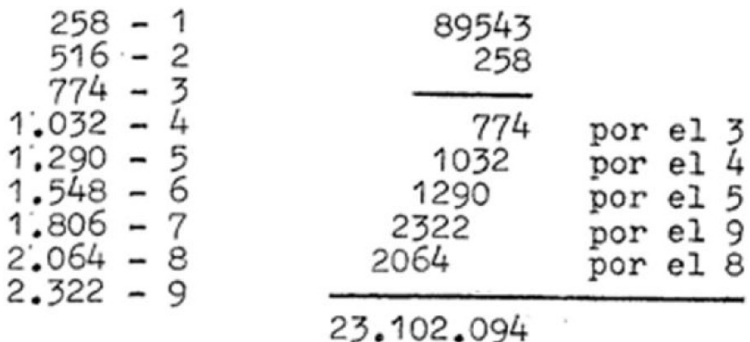

Para evitar "enfado y tiempo" que suponía usar el procedimiento ordinario del multiplicar estaba disponible el "multiplicar restando", método que paralelamente permitía verificar la prueba de la multiplicación. La regla aritmética prescribía como norma para realizar multiplicaciones por este método lo siguiente: añadir tantos ceros como dígitos tenga el multiplicando formado de nueves. De esta nueva cifra restar el multiplicando original como sigue:

\begin{tabular}{rrl}
$34789 \times$ & 347890000 & Resta \\
9999 & 34789 & \\
\cline { 1 - 2 } 347855211 & 347855211 & Producto \\
& 347890000 & Prueba
\end{tabular}

La cuarta regla de la aritmética denominada partición o división tampoco fue ajena a la diversidad de procedimientos que se idearon para su solución. Los métodos breves y curiosos, los que expresamente Morillas (1984: 4) se propuso recopilar, no fueron ajenos a esta regla. Las partes de la división solo tuvieron la diferencia de denominarse partición al dividendo y partidor al divisor, además de partir al dividir. Cuando el partidor venia con ciertas propiedades especiales daban origen a las diversas clases de divisiones: división compuesta, partir por demanda y restando, medio partir y partir por número articulo los que se agrupaban en los dos grandes grupos de la división: del medio partir y partir por completo. ${ }^{22}$

Las operaciones del medio partir, en tanto división entre un solo número, se reducía a sacar la mitad, tercia, cuarta, etc. cuando actuaba como divisor el 2, 3, 4 o otros respectivamente. En los casos en que la partición o dividendo venía compuesto de varios

22 Esto explica las referencias de Morillas y Carlos Daniel Valcárcel acerca de la existencia de 5 operaciones elementales. dígitos las operaciones del medio partir se transformaban en la práctica en operaciones de división completa ante la dificultad de realizarlos casi de memoria.

Las divisiones por el número artículo (un número seguido de ceros o múltiplos de 10) la división se convertía en una simple tarea de "cortar los números" o "cortar tantos números de la partición cuantos son los ceros del partidor" (Morillas, 1984: 62):

$$
\begin{aligned}
& 6319 / 10=6319 / 10 \\
& 7503 / 60=7503 / 60=(1 / 6 \text { de } 750)=1253 / 60
\end{aligned}
$$

donde es posible advertir que la división se reducía a uno del medio partir.

Las modernas operaciones del dividir entre dos o más números en la colonia recibieron la denominación de "partir por números compuestos", diferenciándose solo en la forma de colocar los resultados parciales o restos, además de saber leer en este esquema el cociente y los restos. Una forma similar de partir recibió la denominación de "por demanda" o "danda", el mejor procedimiento de dividir inventado según Morillas, porque satisfacía a cabalidad con un principio de la aritmética práctica colonial: ahorro de papel, tiempo y tinta. Ambos métodos se diferencian en la forma de colocar las operaciones parciales: por encima o debajo del dividendo.

Para ofrecer al usuario más inhábil en las reglas del dividir Morillas recopiló un procedimiento de división denominado "partir restando", muy apropiado para aquellos que solo sabían sumar y restar o aquél que fuese muy rudo para resolver divisiones con muchos dígitos en el divisor. El único recurso al que se debía recurrirse era construir una "una tablilla de los números del partidor" según reglas precisas. Si la variable A fuese el partidor de dos o más dígitos su tablilla respectiva constaría de los siguientes números:

$$
\begin{array}{ll}
\text { (Base) A - } 1 \text { (Base) } 250-1 \\
2 \text { A - } 2 & 500-2 \\
3 A-3 & 750-3 \\
4 A-4 & 1000-4 \\
5 A-5 & 1250-5 \\
6 \text { A }-6 & 1500-6 \\
7 A-7 & 1750-7 \\
8 \text { A - } 8 & 2000-8 \\
\text { 9A - } 92250 \text { - } 9 \text { donde cada cambio de la base o } \\
\text { nuevo partidor reclamaba la confección de su respec- }
\end{array}
$$


tiva nueva tablilla, operación que se podía realizar sin mucho esfuerzo.

\subsection{Reducción de monedas}

Las reducciones de monedas, junto a las de barras, fueron los temas preferidos de los textos de aritmética práctica peruana de los siglos XVI y XVII. Sobre las técnicas matemáticas consignadas en ellos (implícitos o explícitos) debieron ser creación del mundo comercial de los que los que los oficiales reales parece que fueron simples consumidores en la administración de la hacienda real. Esta realidad parece reflejar la poca preferencia en los textos de temas relativos a los quintos y diezmos mineros siendo lo preferencial las reducciones de monedas o precio de las barras de plata. Rastrear las técnicas matemáticas usadas por los oficiales reales de las cajas reales para sus labores cotidianas es casi imposible. Sus borradores de cuenta no nos han llegado, porque es de suponerse que hallado el cálculo deseado estos papeles se desecharan. Es probable que parte de esta información pueda hallarse entre los papeles administrativos de las cajas virreinales.

Afortunadamente este vacío no existe para rastrear las técnicas de cálculo usuales en las cecas coloniales como la de Lima. ${ }^{23} \mathrm{Al}$ menos entre los papeles varios de la colección Moreyra y la sección Casa de Moneda del Archivo General de la Nación de Lima hay hojas sueltas de borradores de cuentas monetarias sin texto aclaratorio alguno, lo que dificulta su desciframiento aunque muchos están relacionadas con la aritmética monetaria. Ahí están descritas con todo detalle las técnicas de cuenta en las labores monetarias, cuya descripción es posible hallar en Morillas. ${ }^{24}$

Las variables que hacían posible la reducción de monedas eran el conocimiento de los múltiplos y submúltiplos de las unidades de peso y valores relacionados con las monedas expresadas en términos de maravedí. ${ }^{25}$ En la América colonial de los siglos XVI y XVII coexistieron diversas monedas cuyo origen era diverso.

23 Buena parte de estas técnicas aritméticas usadas en los procesos de fundición, acuńación o contabilidad fueron recopilados por Carlos Lazo García (1992).

24 Véase el capítulo 131 de Morillas bajo el título "Derechos de la Casa de la Moneda”, p. 464 y ss.

25 Sobre el maravedís como elemento capital de la tecnología monetaria ha ponderado su importancia el iniciador científico del estudio de la moneda colonial don Manuel Moreyra Paz Soldán en varios de sus estudios reunidos afortunadamente en un volumen por el Banco Central de Reserva del Perú (1980).
Algunos fueron monedas de cuenta con antecedente metropolitano (coronas, ducados) o creados en América (pesos ensayado, peso de oro o peso de plata corriente junto a las acuñadas bajo las denominaciones de doblones, patacones, reales y escudos). El ingeniosísimo sistema de la moneda de cuenta fue un mecanismo para habilitar a las barras de plata y oro como monedas mayores, grandes concentrantes de valor, por tener sus seres ciertas seguridades para su uso seguro: quintado, con ley y peso conocidos certificados por los ensayadores mayores, información grabada sobre las barras y adicionalmente en boletas. Las monedas acuñadas desde el punto de vista técnico podían ser a su vez macuquinas (siglos XVI a mediados del XVIII) o circulares con cordoncillo al canto, las primeras labradas en oficinas denominadas hornazas y administrados por los hornaceros y las segundos en las fielaturas bajo la dirección técnica de los fieles de moneda.

Para las reducciones de monedas bastaba tener presente las subdivisiones de las monedas que finalmente terminaban equivaliendo a determinada cantidad de maravedís, el que se redistribuía según la equivalencia de cada moneda en sus divisores menores. Esta unidad mínima de valor (maravedí) era el que facilitaba los cálculos de reducción, que en situación contraria estas serian casi imposibles salvo que se trabajase solo con las unidades de peso de las monedas complicando los cálculos. Cada moneda colonial expresada en términos de maravedís que lo conformaban son los siguientes:

\begin{tabular}{lc}
\hline Unidades & Maravedís $^{26}$ \\
\hline Peso ensayado & 450 \\
Peso de 9 reales & 306 \\
Peso de 8 reales & 272 \\
Peso de buen oro & 450 \\
Peso ensayado de 12,5 reales & 425 \\
Peso ensayado & 450 \\
Ducado & 375 \\
Corona & 350 \\
Doblón & $544^{27}$ \\
\hline
\end{tabular}

Fuente: Diez Freyle (1556), Belveder (1597), Lazo (1992)

26 Submúltiplos o divisores de las unidades: p. ej. un peso ensayado de 450 maravedís de valor contiene a 8 tomines, 96 granos y 450 maravedís o en su defecto un maravedí era la 450 ava parte del peso ensayado, los granos 96 ava parte, los tomines la octava parte. En el mismo sentido entiéndase a las demás unidades y sus divisores.

27 Valor del doblón en maravedís a principios del siglo XVII. 
De toda esta diversidad de unidades monetarias las de cuenta existieron hasta fines del siglo XVII y marginalmente al interior de las partidas contables hasta mediados del siglo XVIII como en la satisfacción de los salarios burocráticos por la Caja Real de Lima. Otras como los pesos de plata corriente existieron coyunturalmente durante la segunda mitad del siglo XVI ante la ausencia de una fábrica monetaria y ordenamiento monetario formal. Las reducciones de monedas podían comprender muchas modalidades. No es gratuito que muchos textos prácticos coloniales contengan en sus páginas informaciones o tablas sobre estos temas, $y$ hasta con casi exclusividad en autores como Juan de Belveder a tenor del contenido de libro.

Las reducciones de monedas podían hacerse bajo dos patrones: reducción directa tomando en cuenta los valores universales de las monedas y reducción de mercado en la que intervenían los intereses que alzaban el valor legal de las monedas, por su alta sobreestimación en situaciones coyunturales como el despacho de armadas o ferias (con intereses que podían fluctuar entre 1 a $50 \%$ ). Este amplio campo de aplicación para la aritmética fue expuesta en cartillas aritméticas de la época, insertando en sus páginas todas las situaciones anteriores que podían presentarse en el mercado. Aún contando con este instrumento auxiliar los usuarios debían sortear dos dificultades: conocer el manejo de las tablas y estar seguros de su confiabilidad, además del requisito elemental de saber leer, escribir y conocer los rudimentos de la aritmética. Para los necesitados de tablas muy exactas (hasta centavos de maravedí) estos sumarios aritméticos no lo podían ofrecer ante la limitación tipográfica del que todavía se lamentaba el cosmógrafo mayor Gregorio Paredes en el periodo de la independencia (Paredes, 1822). Al comercio grosario poco le podía importar estas exigencias, desechables como insignificantes, que en cifras relativas podían significar errores del orden de $1 \%$.

Para comprender las limitaciones al que se exponían los usuarios de las manuales aritméticos prácticos; las palabras de Francisco Juan de Garreguilla a sus lectores son ilustrativas. En la dedicatoria a los lectores de su obra Libro de plata reducida... ilustra el uso de su libro con el siguiente ejemplo: quiero saber el valor de 30 marcos de fino 2.380 maravedís. La solución debía hallarse según sus palabras acudiendo a su obra
[...] se hallará de los mismos marcos, y valen 71 U400 maravedis, y que pesos son plata ensayada, boy al abecedario, y miro donde estan los 30 marcos, y al lado de el hallo el ensayado que hace, que son 158 pesos 5 tomines y 4 granos. Los cuales pesos se han de reducir a corriente. Figuro que se compró o se vendió a 140 voy a la misma plata a buscar en lo alto donde está el 140 y hallo debajo de él en derecho de los 30 marcos 222 pesos 1 real que son el corriente que hacen los 30 marcos, vendidos o comprados a 140, y para saber estos 222 pesos 1 real que tantos patacones son, está debajo del corriente los patacones que hacen en la misma casa: de manera que en una misma plana esta el corriente arriba y bajo los patacones que hacen aquellos corrientes. Y los 222 pesos 1 real hacen patacones 249 patacones 7 reales y por lo consiguiente a los demás precios que quisieren saber conforme en la plaza pasase, lo cual es muy usado desde 140 hasta 144 , que es lo que este libro trata.

Un problema concreta de reducción de moneda suponía calcular la equivalencia de una moneda $\mathrm{A}$ en una moneda $\mathrm{B}$ o viceversa. En la sección cuentas curiosas de su obra Juan Diez Freyle consigna una reducción de moneda bajo el texto siguiente: Si quisieres saber 445 pesos ensayados cuántos ducados hacen (reducción de pesos ensayados a ducados), la solución era 534 ducados. Esta reducción Diez Freyle lo realizó usando el método denominado por él "muy en breve" haciendo lo siguiente (1556: fs. 91 y ss.):

\begin{tabular}{ll}
\hline Peso ensayados: & 445 \\
Su quinto: & $89^{28}$ \\
Sumando: & 534 (ducados) $^{29}$ \\
\hline
\end{tabular}

De análoga forma podríase resolver casi todos los casos de reducción de monedas. Estos métodos abreviados, creemos, no todos fueron compilados en los manuales de este tipo, a satisfacción de algún contador celoso de su hazańa. El recurrir al método anterior significó obviar el multiplicar 445 x 450 y dividir el producto entre 375. Su aplicación siempre

28 Sobre las razones del por qué se saca el quinto y luego se suma, sus fundamentos están en los recursos o trucos aritméticos a los que eran muy aficionados en la colonia, buscado como un camino para abreviar los cálculos con ahorro de tinta, papel y tiempo.

29 La conversión según el método ordinario sería: $445^{*} 450 / 375=534$ cabales. 
era utilísimo cuando no invocaban los temidos picos, fracciones o quebrados.

\subsection{Reducción de pesos}

Las problemas que involucraban unidades de peso, por su uso cotidiano entre el público en general, al igual que sus reglas matemáticas, debieron ser conocidas aún por sectores casi marginados de la sociedad. La complejidad en los patrones metrológicos de peso, capacidad, longitud, y valores usados en la colonia contribuyó a la necesidad de difundir sus reglas matemáticas con amplitud entre el gran público. En los tratos en que esta regla matemática intervenía prácticamente hacía que su campo de aplicación no tuviese limitación: compras y ventas de productos del diario vivir (arroz, pan, fierro, lana, cera, etc.). Como para expresar la pesantez y valor de los productos se emplearon unidades de peso y valor con múltiplos y divisores diversos, en la práctica se impuso la necesidad de reducir a una sola unidad para calcular su precio. Los picos o excesos debían correr el mismo destino inevitablemente, incluso los de la longitud o área.

Un grupo de productos para sus tratos usó exclusivamente como unidades de peso a los quintales, con sus divisores conocidos como libras y arrobas: ${ }^{30}$ cera, acero, fierro, etc. Estas unidades en la vía ordinaria o práctica corriente se acostumbró reducirlos exclusivamente a libras para calcular su precio. Un método sencillo de reducir a libras el peso de un producto, con la concurrencia de quintales, arrobas y libras, "en un instante", era "arrimarle" los quintales a la mano izquierda de la suma de arrobas convertidos a libras, aprovechando de la equivalencia de los quintales y arrobas: 1 arroba $=25$ libras, $2=50,3=75$.

$\mathrm{Si}$ un mercader adquiría fierro con peso de 74 quintales 3 arrobas y 15 libras que en conjunto pesaban 7.490 libras, se podía usar el siguiente procedimiento: triplicar las 3 arrobas para arribar a las 75 libras, sumar estas libras reducidas a las preexistentes:

74 quintales 3 arrobas 15 libras

$$
3 \times 25=\frac{75}{90} \text { libras }
$$

30 La equivalencia entre estas unidades era: un quintal era igual a 100 libras o 4 arrobas, y una arroba a 25 libras.
A las 90 libras lo único ingenioso fue anteponerle "a mano izquierda" 74 (quintales) para completar la reducción mencionada. La anteposición funcionaba siempre por la especial cualidad de equivaler los quintales a 100 libras, en situación distinta sería imposible. En última instancia anteponerle 74 a 90 no era cosa que sumar 90 a 7.400 . El precio se calculaba multiplicando el valor en reales de los quintales por el número de libras finales y del producto "cortar dos números" o dividir entre 100 , por proceder las libras reducidas de una multiplicación anterior por 100 (las cifras originales fueron aumentadas en 100 veces).

Otro grupo de productos se transaba pesándolos exclusivamente en arrobas, libras y sus fracciones para los que se ideó una regla matemática de reducción a cuartos de libra. Similar sistema de unidades fue usado por productos como el azúcar y la lana por contener probablemente en menor peso mayor valor. La reducción de arrobas y libras a cuartos de libras significaba realizar hasta 3 operaciones y eran válidas cuando el precio se fijaba en tantos reales o pesos por cada arroba:

1. Cuadruplicar las libras iniciales

2. "añadir a mano izquierda" las arrobas preexistentes para completar la reducción.

3. Calcular el precio multiplicando las libras reducidas por el precio en pesos por arroba, dividiendo el producto entre 100 .

Aplicando este método a la reducción a un caso concreto puede servir de ejemplo lo siguiente: un mercader compra azúcar a 5,5 pesos la arroba y quiere saber el valor que debe pagar por 45 arrobas y 15 libras de este producto. Siguiendo los 3 pasos anteriores el precio final a pagarse será 250.800 pesos.

15 libras

$15 \times 4=60$ libras

4560 libras reducidas a "cuartos de libra".

$34560 \times 5,5=250,8 \underline{00}$ pesos $=250,8$ pesos

Una regla matemática alternativa simplificada resolvía la reducción anterior recurriendo a una regla curiosa. Este recurso simplificatorio fue posible usando la técnica de reducir a libras y cuadruplicar el precio $^{31}$ que tenía sus propias reglas matemáticas de reducción. Con un segundo recurso curioso se po-

31 Morillas 1984: 267 
día realizar la misma reducción convirtiendo todo a libras para terminar multiplicando ellas por el cuádruplo del precio. Si se compró 639 arrobas 11 libras de lana a 20 reales la arroba, el precio a pagarse será:

$$
\begin{aligned}
& 639-11^{*} \\
& \underline{25}
\end{aligned}
$$

15.975

$$
\begin{aligned}
& \underline{11}+(\text { libras del pico }) \\
& 15.986 * \\
& \underline{80} \text { (reales cuadruplicados } 20 \times 4) \\
& 12.788 \text { reales. }
\end{aligned}
$$

Un tercer grupo de productos, los ligados a los metales argentíferos, usaron como unidad de peso al marco $^{32}$ y su divisor la onza con sus fracciones para los que se creó sus propias de reglas matemáticas de reducción. La reducción era necesaria porque el pico del marco embarazaba las cuentas. Al igual que en todas las reducciones podían recurrirse en este caso a varios métodos. Presentando dos de ellos se entenderá las reglas de este género de reducciones.

La reducción ideal del marco y sus submúltiplos por el método de la plata llana era el más sencillo. Bastaba sacar las partes de la onza respecto de su múltiplo y la de los reales respecto de los pesos corrientes. Si un mercader al comprar una pieza de plata de peso 58 marcos y 6 onzas a 6 pesos 4 reales el marco demandaba de la aritmética luces para saber el precio que debía pagar por ella. Bajo los términos de este problema la reducción demandada era de onzas a marcos y de reales a pesos, haciéndose todo en el acto mismo de la multiplicación de los marcos por el precio. Este método exigió en la práctica la realización de varias multiplicaciones realizadas mentalmente. El ejemplo anterior bajo estos supuestos se resolvía como sigue, de apariencia oscura y que la uso cotidiano a los problemas similares lo convertía en un método fácil:

1. Peso de plata piña

2. Precio por marco

3. Producto de 6 por 58.

4. Mitad de 58 por los 4 reales (mitad de un peso)

32 Las equivalencias del marcos eran: contenía 8 onzas, las onzas a su vez contenían a 8 ochavas, y estas a 6 tomines; y los tomines comprendían en su ser a 12 granos.

58 marcos 6 onzas* 6 pesos 4 reales
5. Mitad de 6 onzas por las 4 onzas (medio marco) 30

6. Mitad de la mitad de 6 onzas por las 2 onzas restantes (1/4 de marco). $\quad 14$ Total: 3817 pesos y reales ${ }^{33}$ respectivamente

La solución anterior cambiaba totalmente al variar los divisores del marco y peso corriente con el concurso de nuevas onzas y nuevos reales. Para similares nuevas situaciones posibles entraban en juego las fracciones siguientes en que se descomponía los reales y onzas (divisores) para resolver la demanda de memoria:

$$
\begin{aligned}
& 1 \text { = un octavo } \\
& 2 \text { = la cuarta parte } \\
& 3=\text { la cuarta, su mitad y la cuarta } 4=\text { la mitad } \\
& 5 \text { = la mitad y su cuarta } 6=\text { la mitad y su mitad } \\
& 7 \text { = la mitad y su mitad y su mitad }
\end{aligned}
$$

Que no eran otra cosa que una representación simplificada redondeada de los quebrados siguientes: $1 / 8,1 / 4,3 / 8,1 / 2,5 / 8,3 / 4$ y $7 / 8$ respectivamente, equivalencias de las onzas o reales con los marcos o pesos. $^{34}$

La complejidad anterior de la reducción del marco para calcular su precio no era en el fondo que un simple producto de quebrados mixtos $(583 / 4 * 61 / 2)$, susceptibles de reducción a heterogéneos para terminar como un nuevo procedimiento. No sabemos si por no apartarse de la norma o por considerarlo como el más expeditivo el método anterior no se siguió involucrando en la solución del problema a los quebrados mixtos, o en el mejor de los casos recurrir a la técnica de los números decimales. ${ }^{35}$

Al ocuparse Morillas de este tipo de problemas presenta uno de sus frecuentes métodos curiosos denominado de números fijos. Usa para sus propósitos como número fijo la cifra reductora 12,5 ó $12 \frac{1}{2}$. ${ }^{36}$

33 Una comprobación bajo procedimientos modernos es: 58,75* 6,5 $=381,875$

34 Una onza equivale a $1 / 8$ de marco y un real a $1 / 8$ de peso porque un marco equivalía a 8 onzas y un peso 8 reales.

35 En la colonia se conocían las fracciones decimales y hasta los números decimales. No nos explicamos el porqué de su no generalización como técnica aritmética por ejemplo en las reducciones.

36 El origen de este número no es otra cosa que la simplificación del problema anterior, trabajándose como modelo con un marco imaginario al que se aproxima la onza para evitar que la operación quede "quebrada". 
El manejo de esta cifra reductora permitió hacer la cuenta con solo ańadir "a mano izquierda el número de los marcos y luego multiplicar llanamente por el precio y cortar del producto dos números (lo que implicaba hacer un división mental entre 100) y lo que queda, ese es el valor del género [...]" (Morillas, 1984: 273). Usando como ejemplo el caso anterior bajo esta técnica los 58 marcos 6 onzas se transforman en: 5.875 de los que los dos últimos dígitos proceden de multiplicar las 6 onzas por el número fijo. El precio final procederá de: $5875^{*} 6,5=381,875 / 100$.

\subsection{Cambios}

Morillas define esta regla como sinónimo de trueque, lo que es discutible, de efectos entre los mercaderes, mencionando tres tipos de cambios: simples en que no se perdía ni se ganaba, cambios con ganancia y cambios con pérdida. Aunque el jesuita no indica los lugares en que eran comunes estos cambios es de suponerse que su uso debió ser ampliamente conocido en los mercados urbano y rural. Los trueques practicados a nivel privado entre el comprador y vendedor eran libres, mientras no afectase los intereses reales. Cuando los cambios involucraban a los metales preciosos del rey su práctica estuvo reglamentado y los encargados de realizarlo fueron los oficiales reales o gremios relacionados con el trato de estos metales.

Los cambios comunes de metal noble por reales involucraron exclusivamente al argento y el oro. En una economía habituada a la moneda como la colonial fue necesaria idear este mecanismo para habilitar a las barras y tejos como moneda mayor, alto concentrante de valor en peso reducido y de fácil transporte. Aceptada la realidad de la moneda mayor en las cajas reales ellas fueron usuales y en ocasiones los oficiales practicaron los cambios de barras por reales o tejos por reales. Estos cambios no eran otra cosa que venta de barras en almoneda pública al precio ofertado por los compradores. Con este mecanismo la caja real se desprendía de barras para proveerse de reales acuñados. En términos contables esta operación se registraba en los libros como "trueque de barras". Esta práctica fue importante en los primeros años después de ordenarse la amonedación obligatoria de la plata en el Perú (1684-1699). Fuera del marco de la Real Hacienda los mismos cambios de barras funcionaron con intensidad actuando como variable relacionante el "precio del ensayado mayor", que osciló entre ciertos márgenes. ${ }^{37}$

Los cambios de barras de plata y tejos de oro por reales se hicieron bajo el patrón referencial del "precio del ensayado" y "precio del peso de buen oro" respectivamente, cuyos equivalentes modernos serían el tipo de cambio por haber funcionado ellos como moneda mayor. El primer precio se expresaba en tantos pesos de a 9 reales por cada 100 pesos ensayados menores de 450 maravedís cada uno. Estos cambios permitieron proveerse de reales a los poseedores de barras o tejos y de ellos a los tenedores de reales.

En el caso del oro la Real Hacienda toleró los cambios al momento del pago del derecho del quinto a un determinado precio. Por esta técnica contable los interesados no tenían que satisfacer este derecho en oro físico o en "especie" si no en reales equivalentes. El patrón o guía para este tipo de cambios fue el precio tributario del oro: determinada cantidad de reales o maravedís por cada peso de buen oro ${ }^{38}$ contable (de fino 22,5 quilates). Esta práctica en la satisfacción del quinto áureo ha complicado la posibilidad de reconstruir la producción del oro, que supone identificar primero los precios tributarios del oro a lo largo de todo el periodo colonial y para Caja Real. ${ }^{39}$ Este mismo inconveniente se dio para la plata pero en menor escala. Para ambos casos reconocer esta limitación significa enfrentarse a realidades como: si por el quinto del oro o la plata se satisfizo en la caja real 1.234 reales, ¿̇cuál fue el $100 \%$ o el total del oro o plata llevado a quintar?, expresado en sus unidades habituales de peso: marcos y onzas para la plata y castellanos y tomines para el oro con su respectiva ley o fino que tuvieran.

Las principales situaciones en que era menester recurrir a los cambios era para intercambiar producto por producto (trueque) y barras y tejos por reales (cambios): un ejemplo de trueque sin ganancia se hizo entre dos mercaderes bajo las siguientes condiciones:

3738 Los precios de la plata oscilaron entre 140 y $147 \%$ pesos de 9 reales por cada 100 pesos ensayados. Un sistema especial de cambios de monedas existente en la colonia fue el sistema conocido como de libranzas por la que girado ésta en una ciudad podía ser cobrado o convertido en moneda en otra con solo exhibir este documento.

38 Al igual que su similar argentífero equivalía a 450 maravedís inicialmente.

39 Nuestras investigaciones al respecto nos indican que cada caja real tenía su propia política al respecto. 
[...] a trueque de géneros como son ruan florete, morlezas y bretańas por iguales partes, esto es tantas varas de uno como de otro. Estos géneros le estaban al mercader a 8 reales los floretes, a 9 reales las morlezas, y a 6 reales las bretañas y el trato es que cada cual a de dar sus géneros a como les está sin que tengan ganancia ni perdida. Preguntase cuantas varas a de dar este mercader de cada uno de los 3 géneros (Morillas, 1984: 304).

La regla matemática de cambios debía solucionar similares problemas. Un segundo caso ocurría al concurrir dos mercaderes al mercado: el uno falto de pańos de Segovia y "sobrado" de terciopelos, el otro falto de terciopelos y "sobrado" de pańos de Segovia. $\mathrm{Si}$ ambos convenían hacer cambio de sus respectivas mercaderías unos por otros bastaba ponerse de acuerdo sobre los precios a que cambiarían. En estos casos de trueques estos cambios eran ventas en que no se recurría al dinero, usado contablemente como un medio facilitador de los cambios. El tecnicismo de la época denominaba a estas operaciones comerciales ventas "a trueque de géneros" y en los casos en que se hiciesen cambios de barras y tejos por reales a estas operaciones las podemos denominar cambio de barras de plata a trueque de reales.

\section{Conclusiones}

Se conocieron durante el periodo colonial tres métodos de calcular: a pluma, de cabeza y mecánicas ${ }^{40} \mathrm{de}$ las que las dos primeras eran las comunes y la última solo quedó en el plano proyectista o en simple proyecto. A pluma implicaba coger pluma y papel para ensayar un cálculo o resolver un problema recurriendo a cualquier método conocido.

Los diversos métodos ideados para resolver una cuenta tenían como objetivo final "ahorrar números" con la idea de consumir menos papel y tinta. Otro objetivo era resolver un problema "en un instante" o buscar "atajo admirable para sacar de una vez" una cuenta. El mejor contador era considerado a aquel que con "menos número sacare una cuenta".

Para simplificar los cálculos se idearon un conjunto de tablas que eran una especie de "atajo de atajos" a la que cualquiera podía recurrir para resolver

40 Documentado para México y no para el Perú. un problema. La elaboración de estas tablas debió ser para la época una tarea titánica y hoy es muy fácil recrear estas tablas con el auxilio de hojas de cálculo o con la programación en cualquier lenguaje conocido.

Miguel de Rada o el Mercurio Peruano al considerar al comercio como una actividad práctica juzgaban a la vez como una ciencia, porque esta actividad no podía ser confiada a la improvisación. Todo buen comerciante debía "tener en la uña" todas las reglas de su oficio y sujetar sus negocios a procedimientos racionales. Este pensamiento justificó la elaboración de los diversos manuales prácticos de aritmética.

Los diversos textos de matemática práctica no se ocupan de la teoría, de la definición del número si no de las diversas "cuentas husuales y necesarias en este Reyno del Peru" relacionadas o que involucren el uso de las unidades de peso, medida y valor que eran comunes en el Perú, temas que eran ausentes en los textos extranjeros como los editados en Europa o hasta la misma España. Estas cuentas y reglas eran las más usuales y necesarias para todo tipos de comerciantes.

Los libros escritos sobre el tema eran a la vez que utilitarias para todo tipo de comerciantes estaban dirigidos a todo público interesado que quisiera aprovechar los conocimientos que en sus páginas se ofrecían, que no sabían ni contar, por lo tanto fueran capaces de no cometer errores y evitar que otros los engañen. El pico de las cuentas, donde se podía recurrir a estos libros, eran las épocas de despacho de flotas para Tierra Firme y México, o en cualquier ocasión que se requiriese hacer una conversión.

\section{Bibliografía consultada}

Atienza, Joseph (1776). Methodo nuevo, fácil, breve, y curioso de arismetica, teórica, y practica, con el que qualquiera podra, sin maestro, aprender a contar desde el alphabeto, hasta lo mas sublime de la facultad, con muchas reglas nuevas, y curiosas. Madrid: Oficina de Pablo Madrid, segunda edición.

Belveder, Juan de (1597). Libro general de las reducciones de plata y oro de diferentes leyes y pesos, con otras reglas $y$ avisos muy necesarios para estos reinos del Perú. Lima: Antonio Ricardo.

Diez Freyle, Juan (1985 [1556]). Sumario compendioso de las cuentas de plata y oro que en los reinos del Perú son necesarias a los mercaderes y todo género de tratan- 
tes, con algunas reglas tocantes a la aritmética. Madrid: Edición facsimilar por Cultura Hispánica del Instituto de Cooperación Iberoamericana.

Espinoza Soriano, Valdemar (2012). La Real y Pontificia Universidad de San Marcos en el siglo XVII. Sus aportes cientificos. Lima: Unidad de Impresiones y Publicaciones de la Facultad de Ciencias Sociales de UNMSM.

Garreguilla, Juan Francisco de (1607). Libro de plata reducida que trata desde 30 marcos hasta 129 de toda ley de 2380 con su abecedario al margen, con tres tablas a la postre. Lima: Francisco del Canto.

Hernández Ch. y Miño G., Manuel (coordinadores). Cincuenta años de historia en México. México: El Colegio de México, vol. 2.

Lazo G. Carlos (1992). Economía colonial y régimen monetario. Perú siglos XVI-XIX. Lima: Fondo Editorial del Banco del Banco Central de Reserva del Perú, 3 vols.

López Piñero, José María (1982). La ciencia en la historia hispánica. Barcelona: Salvat Editores S.A.

Macera, Pablo (1977). Trabajos de Historia. Lima: Instituto Nacional de Cultura, 4 vol.

Montesinos, José L. (2007). Ciencia y teología (Física. Matemáticas y Teología en los orígenes de la ciencia moderna). Tegueste: Ediciones Idea.

Moreno Corral, Marco Antonio (2008). El primer texto matemático de América. En revista Ciencia, octubre-diciembre.
Moreyra y Paz Soldán, Manuel (1980). La moneda colonial del Perú. Capitulos de su historia. Lima: Banco Central de Reserva del Perú.

Morillas, Diego de (1984 [1693]). Aritmética peruana. Lima: Seminario de Historia Rural Andina, 4 vols.

Paredes, José G. (1822). Lecciones de matemáticas. Tomo 1 Aritmética e introducción al álgebra. Lima: Imprenta del Estado.

Postigo, Luis (1977). Matemáticas. Barcelona: Edit. Ramón Sopena S.A.

SAldías, Pedro de (1637). Tablas para la reducción de barras de plata de todas leyes a marauedis, pesos ensayados y de a ocho reales. Sevilla: Francisco de Lyra.

Sedgwick, W.T y Tyler, H.W. (1950). Breve historia de la ciencia. Buenos Aires: Edic. Argos.

SuÁrez, Margarita (2014). Reforma, orden y concierto en el Perú del siglo XVII: el arbitrio de Joan de Belveder. En Anuario de Estudios Americanos, 71, 1, enero-junio, pp. 25-46

Trabulse, Elias (1984). El circulo roto. México: Fondo de Cultura Económica.

Valcárcel, Carlos D. (1968). Historia de la educación colonial. Lima.

Villaseca F. (1985). Salvador. Matemáticas y astronomía en la historia de Cuba. En Quipu, Revista de la Sociedad Latinoamericana de Historia de la Ciencia, Vol. 2, Núm. 2, Mayo-agosto 1985, pp.185-212. 